\title{
유엔총회 2위원회 종결
}

1. 12.19 (월) 총회 2 위원회는 잔여 결의안 및 61 차 총 회 2 위원회 의제를 채택하고 토의를 종결함.

2. 금번 60 차 총회 2 위원회는 9 월 정상회의시 합의 사항을 보다 구체적으로 논의하는 후속협의의 성 격이 강하였는 바, 대부분 9 월 정상회의 결과문서 와 기존 합의의 틀 내에서 문안 합의가 이루어짐.

口 G-77은 9월 정상회의 결과문서 보다 개도국들에 게 더 유리하고 상세한 내용을 결의안에 반영하고 자 하였으나, 선진국 특히 미국측이 9월 정상회의 결과문서 내용을 넘어서는 제안에 대해서는 강한 유보적인 입장을 보여 기존 합의 내에서만 컨센서 스가 이루어짐.

3. 지금까지 2 위원회 결의안은 팔레스타인 문제 등 정치적인 사안을 제외하고는 모두 컨센서스에 의 해 채택되어 왔으나, 금번 회의에서는 시간적 여 유가 없다는 이유로 합의가 이루어지지 않는 조항
이 투표에 회부되는 경우가 증가하였는 바, 이는 유엔개혁 협의과정에서 나타난 개도국간 대립구 도가 제 2 위원회 결의안 채택 과정에도 큰 영향을 미친 것으로 분석됨.

첨부 : 주요 결의안 내용 및 논의결과

[자료 : 주국제연합 대표부] 


\section{주요 결의안 내용 및 논의 경과}

\section{1. 부패방지 및 불법자금 반환(L.54)}

\section{가. 주요 내용}

ㅁ유엔 반부패협약 이행을 위한 각국의 국내법 마련을 촉구

ㅁ 뇌물, 돈세탁, 불법 자금 송금 등을 포함한 모든 종류의 부패방지 및 유엔 반부패 협약의 원칙에 따른 불법 자금의 반 환 권고

ㅁ부패방지 및 불법자금 반환을 위한 지역 및 국제사회의 협력 요청

ㅁ 부패방지를 위한 민간부문의 조치를 환영하고, 기업들의 책임을 계속 개선해 나갈 필요성 강조

나. 주요 논의경과

ㅁ결의안 제목에서 불법 자산의 반환 관련, 본국으로의 환원을 강조하려는 개도국과 유엔반부패 협약의 일관성하에서 환원을 강조하려는 선진국의 의견을 절충, consistent with the UNCAC를 추가함과 동시에 "to the countries of origin" 앞에 "in particular" 를 삽입

ㅁ돈세탁과 부패 사이의 직접적 연관성이 없음을 리히텐슈타인이 강하게 주장, 돈 세탁에 초점을 맞춘 몇몇 문단에 이 의를 제기, 문안 수정

ㅁ러시아는 부패와 테러리즘 사이의 연관성을 강조하고자 하였으나, 여타국의 반대로 반영되지 않음.

\section{2. 개발을 위한 과학과 기술(L.59)}

\section{가. 주요 내용}

ㅁ아래사항에 대한 공약을 확인

- 개도국의 특별한 요구를 해소하기 위해 연구와 개발을 위한 현재의 메카니즘과 이니셔티브를 강화

- 개도국에 대한 적절한 기술이전 및 접근 등을 촉진

- 인적자원 및 과학 · 기술 발전을 위한 국가전략수립 및 증진을 지원

- 재생가능 에너지 자원 개발 증진 및 지원

- 상호 합의하는 조건에 따라 기술을 이전하는 공공 및 민간부분의 투자를 촉진할 수 있는 개별 국가 및 국제적 정 책을 이행

- 새로운 농업기술 개발을 위한 개도국의 개별적, 집단적 노력 지원

ㅁ개발을 위한 과학 및 기술위원회(CSTD)와 UNCTAD 및 관련 기구의 개도국 노력 지원 요청 및 권고

ㅁ생명공학 분야에서의 개도국의 역량 마련을 위한 관련 국제기구들의 지원 노력 인정

나. 주요 논의경과

지난 회의시까지 폐지 논란이 있었던 CSTD의 향후 기능과 관련한 논란이 있었음. 
- 개도국은 정보사회 정상회의 준비과정에서의 CSTD의 기여 및 유엔 정상회의 결과 이행을 위한 CSTD의 역할을 강조함으로써 동 위원회 기능 강화를 시도하였으나, 선진국의 반대로 동 문안 삭제

- 현 임무내에서 농업, 농촌개발, ICT, 환경관리 등 개도국의 특별한 필요를 해소하기 위한 장을 제공한다는 문안에 만 합의

ㅌU는 biosafety 관련 주요 협약인 카르타헤나 의정서 규정에 부합하는 생명공학 분야 활동을 강조하였으나, 미국측 이 카르타헤나 의정서에 관한 어떤 언급도 수용할 수 없다는 강한 입장을 견지, 결의안에는 반영되지 않음.

\section{3. 인적자원개발 결의안(L.49)}

\section{가. 주요 내용}

ㅁ세계화와 정보 · 통신기술의 발달이 개도국의 인적자원개발에 도전이 되고 있으며, 이 분야에 있어 선 · 후진국간 격 차가 심해지고 있다는 것을 인식

ㅁ고숙련, 고학력 인력의 이동이 인적자원 개발과 지속가능개발에 미치는 영향을 유의하고, 이들의 이동으로 인한 긍정 적인 영향을 최대화하기 위한 전세계적, 포괄적 접근이 필요함을 강조

미속가능개발을 증진하는데 미치는 인적자원 개발의 중요성을 인식하고, 교육, 보건 및 과학 - 기술을 포함한 사회간 접자본과 역량 개발에 초점을 둔 투자촉진정책 채택을 요구

ㅁ인적자원개발에 양성평등 개념을 도입, 관련 정책과 전략 수립 및 이행에 대한 여성의 완전한 참여를 보장할 필요 강조 ㅁ경제성장, 빈곤퇴치, 기본적 사회서비스 제공 등을 결합한 전 부문에 걸친 인적자원 개발 접근책 도입 촉구

ㅁ교육, 훈련, 지속 공유 등을 촉진하기 위한 정보 · 통신 기술의 전략적, 혁신적 활용을 장려하고, 2005년 11월 튀니지 에서 개최된 제2차 세계정보사회 정상회의에서 채택된 Tunis Commitment와 Tunis Agenda for the Information Society의 이행의 중요성을 강조하며, 이와 관련 국제사회가 개도국의 노력을 지원할 것을 요구

나. 주요 논의경과

ㅁ선 · 후진국간 지식 및 정보 · 통신기술의 격차 증대 문제, 고숙련· 고학력 인력의 이동 문제에 관한 표현을 어떻게 기 술하느냐에 대해 $\mathrm{G}-77$ 과 미국측의 의견이 대립하였으나, 절충된 문안으로 타결

뮈니지 정보사회 정상회의 결과문서를 환영하는 $\mathrm{EU}$ 측의 문안과 동 문서 이행의 중요성을 강조하는 G-77측의 문안 이 대립되었으나, $\mathrm{G}-77$ 측 문안으로 타결

$\square \mathrm{G}-77$ 초안에 인적자원개발 관련 교육과 보건의 중요성을 강조하고, 인적자원 개발을 위한 통합적인 접근책을 촉구 하는 $\mathrm{EU}$ 및 미국측의 문안 추가

\section{4. 국제이민과 개발(L.62)}

\section{가. 주요 내용}

ㅁ 2006.9.14 15간 국제이민과 개발에 관한 고위급 대화를 개최하는 것을 결정하고, 각료급 또는 가능한 최고위급에서 참여할 것을 권고 


\section{첨부}

ㅁ 고위급 회의는 현재 재원내에서 4 개의 전체회의와 4 개의 원탁회의로 구성할 것을 결정

$\square 4$ 개의 원탁회의의 주제는 다음과 같이 결정

- 경제· 사회 개발에 있어 국제이민의 영향

- 이민자들의 인권보호를 위한 조치 및 불법이민방지 방안

- 송금을 포함한 국제이민의 다차원적인 측면

- 국제이민 관련 파트너쉽과 역량 증진

2006년에 현재의 재원내에서 NGO, 시민사회 및 민간부문 대표들이 참석하는 비공식회의(1일) 개최

ㅁ인구개발위원회, 사회개발위원회 및 여성지위위원회는 고위급 회의 개최전 각각의 임무범위내에서 국제이주 문제를

논의하여 그 결과를 $\mathrm{ECOSOC}$ 에 보고

나. 주요 논의경과

ㅁ 2006.9.14 15 개최 예정인 국제이민 및 개발관련 고위급 대화의 구성 부분인 4 개의 원탁회의 개최에 추가비용이 소요되는지 여부가 마지막까지 쟁점

- 사무국측이 당초 동 원탁회의 개최에 55,200 불이 추가로 소요된다는 평가를 한데 대해, 스위스가 OP7의 "four interactive roundtables" 다음에 "within existing resources"를 삽입하여 추가예산 소요 가능성을 제거하려 하였 으나, 사무국측은 그럼에도 불구하고 PBI가 여전히 발생한다고 설명

ㅁ이에 미국측이 회의개최 직전 $\mathrm{OP7}$ 조항만 표결에 회부한 바, 찬성 159 , 반대 2(미국, 일본), 기권 1 (이스라엘)로 채택

- 전체 결의안은 컨센서스로 채택

ㅁ우리는 동 결의안 $\mathrm{OP7}$ 관련, 사무국측의 PBI 발생 입장 설명 이전에 이미 전체 결의안이 컨센서스로 합의되었고, 미 국 등 일부 국가를 제외하고는 컨센서스가 형성되어 있어, 찬성 투표

\section{5. 남남협력(L.61)}

맘남협력 증진과 이행의 주책임은 개도국에 있으며 이러한 맥락에서 국제사회가 남남협력 확장을 위한 개도국의 노 력을 지원할 필요 강조

ㅁ개도국간 지역통합 이니셔티브가 남남협력의 중요하고 가치있는 형태이며, 세계경제로의 유용한 통합을 위한 조치라 는 것을 인정

ㅁ남남협력 증진을 위한 추가재원 동원의 필요성을 인정하며, 이러한 맥락에서 총회 $57 / 263$ 결의안의 유엔기여금 서약 회의에 남남협력 증진을 위한 자발적 기여금을 포함시키기로 한 결정을 강조

$\square$ UNDP가 관련 위임과 자발적 성격을 유지하는 가운데 남남협력 증진을 위한 자발적 기여금의 이름을 개명할 것과 이를 남남협력과 삼각 이니셔티브를 지원 및 증진하기 위한 주요 유엔 신탁기금으로 지정할 것을 권고 


\section{6. 글로벌 파트너쉽(L.38/Rev.1)}

\section{가. 주요 내용}

파트너쉽은 다양한 당사자간 자발적이고 협력적인 관계이며, 각국 정부 공약의 보완적 역할로서 $\mathrm{MDG}$ 를 포함한 국제 적으로 합의된 목표 달성을 위한 자발적 파트너쉽의 기여의 중요성을 강조

ㅁㅏㅏ트너쉽은 국가우선순위, 국내법 및 국가개발전략과 일치되어야 한다는 것을 강조

ㅁ유엔 파트너쉽으로 하여금 투명성, 책임성, 지속성에 기반한 파트너쉽을 위한 공통의 체계적 접근법 개발을 계속할 것을 장려

$\square$ Global Compact에 의해 장려되는 것과 같은 책임있는 기업 관행을 장려하고, Global Compact 사무소로 하여금 이 러한 관행을 공유하고 긍정적인 조치를 증진할 것을 장려

ㅁ 사무총장이 회원국과 협의 현재의 재원내에서 영향 평가 메커니즘을 촉진할 것을 요청

파트너쉽에 참여하고 있는 유엔 시스템내의 모든 기구에 대해 그 기구의 권위와 독립성을 확보하고, 파트너쉽에 관 한 정보를 정기보고에 포함시킬 것을 촉구

ㅁ유엔 파트너에 대해 정부 및 유엔기구 등에 대해 적절한 정보제공 및 교류를 촉구

\section{나. 주요 논의경과}

ㅁ 선진국은 민간부문의 역할을, 개도국은 기업의 사회적 책임(corporate social responsibility)을 강조하는 가운데, 문 안 절충

물리는 동 결의안에 공동제안국으로 참여

\section{7. 내륙개도국 문제와 관련된 조치(L.68)}

\section{가. 주요 내용}

$\square$ 회원국과 유엔 기구, 관련 지역기구 및 국제금융 - 개발 기구들이 알마티 행동계획에서 합의한 5 가지 우선순위와 관 련된 조치를 취하 것을 권고

$\square$ 원조국과 다자 및 지역금융 - 개발 기구들이 내륙 및 경유 개도국에 대해 수송 및 저장시설 개선을 위한 적절한 금융 및 기술 지원을 할 것을 권고

ㅁ 수송시설 개선에 대한 지원이 내륙 및 경유 개도국의 전반적인 경제 개발 전략에 통합되어야 함을 강조

$\square$ 회원국들은 2004.8.1 WTO 일반이사회 결정과 알마티 행동계획에 포함된 바와 같이 무역시설과 관련한 내륙개도국 의 특별한 필요를 지원할 것을 권장

$\square$ 유엔 관련 기구들이 알마티 행동계획을 관련 사업 프로그램에 포함할 것과 조화되고 일관된 기술지원 프로그램을 통 해 내륙 · 경유 개도국에 대한 지원을 계속할 것을 권장

나. 주요 논의경과

ㅁ 내륙개도국의 무역시설과 관련한 조항이 마지막까지 쟁점사항이었으나, 상기 문안으로 절충 


\section{첨부}

\section{8. 이민자 송금촉진 및 비용 감소(L.15/Rev.1)}

\section{가. 주요 내용}

뫼원국 정부와 여타 관련 기관이 국내법에 따라 아래를 포함하여 수신국으로의 이민자 송금을 촉진하는 조치 도입을 검토할 것을 권장

- 송금관련 공식적 수단으로의 절차를 간소화하고 촉진

- 이민자들을 위한 금융 서비스에 대한 접근과 이용을 촉진

$\square$ 개발 파트너와 관련 국제기구들이 이민자 송금 흐름을 촉진할 수 있는 역량 구축을 위한 개도국의 노력을 지원할 것 을 권고

\section{나. 주요 논의경과}

ㅁ이민자 송금 비용을 줄이기 위한 구체 실천방안에 대해서는 합의를 하지 못하여 핵심 내용만 유지하고 나머지는 삭제

\section{9. 여성과 개발}

가. 주요 내용

뫼원국 정부가 경제 · 개발정책 수립 및 이행에 있어 양성평등을 보편화하는 전략을 증진할 것을 촉구

$\square$ 여성과 소녀에 대한 폭력이 평등, 개발 및 평화 달성에 장애가 됨을 인정하고, 회원국들이 이들에 대한 폭력을 방지 하는 정당한 노력을 기울일 의무를 지원할 수 있는 전략을 이행할 것을 촉구

$\square$ 회원국 정부가 은행 융자, 주택융자 및 여타 형태의 금융대부에 관한 여성의 차별을 제거하기 위한 모든 적절한 조치 를 취할 것을 촉구

ㅁ빈곤퇴치, 여성의 권한 강화, 고용 창출에 있어 소액금융의 역할을 인정하고, 국제금융기구 지원을 포함하여 현재의 소액금융기관의 역량을 강화할 것을 권장

\section{나. 주요 논의경과}

ㅁㅇ성에 대한 폭력 대처 방안을 보다 강력하고 자세하게 기술하려는 선진국과 원칙론만 언급하려는 개도국간 입장에 차이가 있었으나, 현재의 문안으로 절충

ㅁ결의안내 작년과 유사한 내용의 반복으로 분량이 지나치게 많아진 것을 노르웨이가 아주 간략한 내용으로 수정(미국 등 선진국 지지)하려 하였으나, G-77측의 반대로 그대로 유지

마지막까지 ODA관련 문안에 합의를 이루지 못하다가 개발재원 결의안 관련 문안으로 합의

\section{0. 제3차 유엔 최빈국 회의(L.32/Rev.1)}

\section{가. 주요 내용}

ㅁㅊ비ㄴㅣㅐ도국 개발을 위한 브뤼셀 행동계획의 미흡한 이행에 대한 깊은 우려 표명

ㅁ2006.9.19 20간 뉴욕에서 브뤼셀 행동계획 검토를 위한 고위급 회의 개최를 결정

ㅁ60차 총회 기간중 3일간 가급적 2006.9.4 6간 준비회의 개최 
$\square$ 총회 의장에게 $\mathrm{NGO}$, 시민사회단체 및 민간부문 대표들과 하루의 비공식 청문회 개최 요청 최빈개도국 자체의 브뤼셀 행동계획 이행에 대한 국가적 검토를 시행할 것을 촉구

$\square$ 사무총장이 고위급회의시 각 최빈개도국에서 2 명의 대표가 참가할 수 있도록 예산 이외의 재원을 동원할 것을 요청 하며, 회원국과 여타 개발파트너 등의 자발적 기여금 제공을 촉구

\section{나. 주요 논의경과}

ㄴLDC 행동계획 이행 점검을 위한 고위급 회의(2006.9.19-20) 이전에 준비회의를 개최하는 조항(OP6)에 대해 G-77, 미국, $\mathrm{EU}$ 등간에 의견 차이 노정

- 개도국은 5 일간의 준비회의 개최를, 미국, $\mathrm{EU}$ 등은 준비회의를 하루로 단축할 것을 주장하여 3 일간의 준비회의를 개최하는 것으로 대체적으로 의견 접근(동 준비회의에 $\mathrm{EU}$ 는 유연한 입장, 미국은 반대)

※ 사무국측은 동 고위급 회의가 유엔총회 회의의 일부로 개최될 경우, 223,200불의 추가예산이 소요되는 것으로 평가

믈ㄹㄴㅏㅏ 최종적인 합의를 이루지 못하고 있는 가운데, G-77측이 추가적인 합의를 회피함에 따라, EU는 OP6 관련 회 의 직전 별도의 수정안(L.69) 제안

- 동 수정안은 준비회의 관련 $\mathrm{G}-77$ 측의 문안을 유지하는 가운데, 준비회의 결과 short declaration을 채택하는 것을 고려할 것을 권고하는 내용 추가

EU측 수정안에 대한 투표결과, 찬성 45(EU, CANZ, 러시아, 한국 등), 반대(G-77 등), 기권 5(일본 등)으로 부결

- 이후 미국측이 OP6만을 표결에 회부, 찬성 117, 반대 1(미국), 기권 45(EU, CANZ, 일본, 한국 등)으로 부결

ㅁ전체 결의안은 투표없이 컨센서스로 채택

무리른 결의안 OP6 관련 표결시, G-77측이 마지막까지 컨센서스를 이루기 위한 노력을 회피하였고, EU측의 문안이 합리적인 점을 고려, $\mathrm{EU}$ 측의 수정안에는 찬성하였으며, 결의안 원안 OP6에는 기권 투표

\section{1. 국제금융시스템과 개발(L.67)}

\section{가. 주요 내용}

ㅁ 개도국 전체가 자본 순유출을 겪고 있다는 것을 유의하고, 사무총장에게 국제금융기구와 협조, 보고서에서 그 이유를 분석할 것을 요구

ㅁ국제금융 안정과 지속가능한 성장의 중요성을 강조하고, 이와 관련하여 IMF와 금융안정 포럼에 의해 취해진 조치를 환영

ㅁ금융리스크에 대한 저항을 증가시키는 국가차원의 노력의 중요성을 강조하며, 국가의 부채 부담에 대한 평가의 중요 성을 강조

ㅁㄱㄱㄱ제금융 및 은행 기관이 위험도 평가 메커니즘에 대한 투명성 향상을 검토할 것을 권고

믈레튼우즈 기구에서 개도국과 과도기에 있는 국가들의 목소리를 증대시키는 문제의 중요성을 강조하고, IMF 쿼터 검토 맥락에서 진전이 있는 것을 고려하며 이 분야에서 진행중인 작업을 향상시킬 것을 강조

ㅁ 금융기준 및 규약 형성에 있어 개도국의 효과적이고 형평성이 있는 참여를 확보하는 것이 긴요함을 강조 


\section{첨부}

ㄱ개발 목적을 위해 특별인출권(SDR)을 사용하자는 제안을 유의하며, 특별인출권 할당에 있어 어떠한 평가도 IMF 합의 서의 조항과 관련 절차를 존중하여야 한다는 것을 고려

나. 주요 논의경과

ㅁ 개도국의 국제금융체제의 투명성과 책임성을 강화하고 개도국의 입장을 더욱 잘 반영할 수 있는 체제를 만들 것을 주장한 반면, 선진국은 금융리스크에 대한 저항을 증가시키는 개별 국가의 노력을 강조

마지막까지 개발을 위한 특별인출권 문제에 합의를 이루지 못하다가 몬테레이 컨센서스 문안으로 합의하는 등 쟁점 이 되는 사안은 대체적으로 9월 정상회의 문안과 몬테레이 컨센서스 문안의 틀 내에서 합의 미국, $\mathrm{EU}$ 는 $\mathrm{EOV}$ 를 통해 자본순유출은 무역 및 투자 확대로 이루어질 수 있는 사실을 상기시킴.

\section{2. 개발재원 국제회의 이행 및 후속조치(L.72)}

\section{가. 주요 내용}

ㅁ 국제적 규범 준수와 국가적 정책 재량(policy space)간 적절한 균형 유지가 필요하다는 것을 유의할 것을 강조

ㅁ선진국들이 개도국에 대한 외국 직접투자 흐름을 촉진하고 장려할 것과, 개도국들은 투자유치를 위한 적절한 환경 조 성을 위해 계속 노력할 것을 촉구

ㅁㅏㄶㄶ은 선진국들이 2015년까지 GNP의 0.7\%, 2010년까지 0.5\% ODA 제공 목표 달성을 위한 시간 계획을 제시함으로 써 가능해진 개발재원의 증가를 환영하며, 그렇게 하지 않은 국가들이 구체적인 노력을 기울일 것을 촉구

ㅁ새로운 개발재원 관련 진전을 인정하며, 새로운 개발재원의 대상에 대해 더 검토할 것을 결정

ㅁ몬테레이 컨센서스 이행 점검을 위한 후속 개발재원 국제회의를 2008년과 2009년 사이에 개최할 것을 결정

$\square$ 카타르의 동 회의 주최 제안을 환영

ㅁ61차 총회시 개발재원 국제회의의 정확한 개최 일자를 포함하여 준비과정을 시작할 것을 결정

나. 주요 논의경과

ㅁ몬테레이 컨센서스 이행 검토 문제를 위한 개발재원 국제회의 개최 시기가 주요 쟁점이 되었는 바, 카타르측이 제안 한 2007년 개최에 대해 미국, EU 등이 반대, 이를 2008년과 2009년 사이 시점으로 절충(구체시기는 61차 총회에서 결정)

- 개최 장소 문제는 카타르측의 제의에 대해 미국측이 매우 유보적인 입장을 견지, 카타르의 제안을 유의한다(note with appreciation)는 문안을 제시하기도 하였으나, 궁극적으로는 이를 환영(welcome)한다는 데 합의

$\square \mathrm{ODA}$ 와 새로운 개발재원 문안에 대해 진전된 상황을 포함하고자 하는 $\mathrm{EU}$ 등의 노력이 있었으나, 미국측의 유보적인 입장으로 9월 정상회의 문안을 그대로 인용하는 선으로 절충

- 다만, 새로운 개발재원 관련 진전을 인정하며, 새로운 개발재원 메카니즘의 대상에 대해 더 검토할 것을 결정한다 는 문안 추가 


\section{3. 외채 위기와 개발(L.51)}

\section{가. 주요 내용}

ㅁㅊㄱ근 G-80 제안하고 있는 브레튼우즈 기구가 승인한 HIPC 이니셔티브 수혜 대상국가들에 대해 $100 \%$ 부채탕감조 치 환영

먹ㄱ정 채무상환 관리는 개도국의 성장 및 $\mathrm{MDG}$ 이행에 필수적

ㅁ HIPC 이니셔티브 대상국가 선정 기준에 유연성 부여 필요

ㅁ HIPC 이니셔티브에 해당하지 않는 중소득 국가들의 채무문제 해결 방안 강구 필요

- 출자전환(Debt for Equity in MDG Projects) 방식에 관한 파리 클럽의 최근 토의 및 평가를 유의

ㅁ개도국에 대한 공여국의 양자 무상지원 증액 권고 및 해당 개도국은 보건, 교육분야 투자 필요성 인식

마연재해로 피해를 입은 개도국의 채무 상환에 유연성을 부여한 채권국의 노력 환영

\section{나. 주요 논의경과}

$\square$ 개도국은 HIPC 대상 국가 확대 및 면제 가능 채무범위 확대 등을 주장하고 선진국이 개도국에 채무 변제의 방법으 로 주어진 자금이 차감되지 않도록 하는 등의 선진국에 대한 요구사항을 강화코자 노력

만ㄴ면, 선진국은 HIPC 대상 국가 확대 면제 가능 채무범위 확대 요구 등에 대해서는 강력 반대하였으며, 개도국의 거 시경제정책 수립 및 채무상환 능력 증대를 위한 정치 · 경제 · 사회 개혁 노력 강조

ㅁHIPC 대상국 및 중소득 국가에 대한 출자전환 같은 채무 변제 방식에 대해 선 - 개도국간 의견 대립이 있었으나, 출 자전환 방식에 관한 파리클럽의 최근 토의 및 평가를 유의(take note of)하는 선에서 문안 타결

$\square \mathrm{G}-77$ 측의 자연재해로 피해를 입은 개도국에 채무상환 유예 요구에 대해 미국 등 선진국이 문안 삭제를 주장하였으 나, 최근 몰디브에 대한 LDC 지위연장 결의안 채택 등을 감안, 채권국의 노력을 환영하는 문안으로 절충 